\title{
Technical note: Implementation of prescribed (OFFLEM), calculated (ONLEM), and pseudo-emissions (TNUDGE) of chemical species in the Modular Earth Submodel System (MESSy)
}

\author{
A. Kerkweg, R. Sander, H. Tost, and P. Jöckel \\ Air Chemistry Department, Max-Planck Institute of Chemistry, P.O. Box 3060, 55020 Mainz, Germany
}

Received: 20 April 2006 - Published in Atmos. Chem. Phys. Discuss.: 27 June 2006

Revised: 29 August 2006 - Accepted: 31 August 2006 - Published: 4 September 2006

\begin{abstract}
We present the submodels OFFLEM, ONLEM, and TNUDGE for the Modular Earth Submodel System (MESSy). Prescribed emissions from input files are handled by OFFLEM. ONLEM deals with online-calculated emissions, i.e., emissions that are calculated during the simulation. The submodel TNUDGE uses the "tracer nudging" technique for pseudo-sources and -sinks. For species with highly uncertain emission fluxes and/or with sufficiently long lifetimes, e.g., $\mathrm{CH}_{4}$, it is common to create such pseudofluxes by prescribing the observed mixing ratio of the species at a given boundary (e.g., the mixing ratio of methane at the surface, or the ozone mixing ratio at the tropopause). All three submodels substantially simplify the inclusion of emissions into a model. Specific emissions can easily be switched on or off. New prescribed emissions can be included without rewriting any code. New online emissions only require one additional subroutine containing the new parameterization. A major advantage is that input fields at arbitrary resolution can be used. The problem of incompatible grids between emission data and model is overcome by utilizing the MESSy data import interface. To further simplify the creation of new offline emission data, the preprocessing program EDGAR2NC is provided. EDGAR2NC transforms files from the EDGAR format into the netCDF format which is required by OFFLEM. The presented routines are a part of the community modeling project MESSy and can be made available for use to the atmospheric modeling community.
\end{abstract}

\section{Introduction}

In the past the implementation of new emissions into an atmospheric model was a very time-consuming task, especially due to file format conversions. Most impractical was (for

Correspondence to: A. Kerkweg

(akerkweg@mpch-mainz.mpg.de) many models) the need to have matching grids between the input field and the model grid, thus forcing the user to interpolate the input data in advance for each specific model resolution. This is avoided here by using the MESSy data import interface which is based on the general regridding tool NCREGRID ${ }^{1}$ by Jöckel (2006).

In the following sections the details of the submodels will be described. In Sect. 2.1 the submodel OFFLEM and the conversion tool EDGAR2NC are presented. In Sect. 2.2 details about the online calculated emissions (i.e., the submodel ONLEM) are given and Sect. 2.3 is dedicated to the pseudofluxes calculated by TNUDGE. The text focuses on the main aspects of these three submodels but, in the interest of space, omits a number of technical aspects. For a full description, the reader should consult the user manual in the electronic supplement to this paper at http://www.atmos-chem-phys. net/6/3603/2006/acp-6-3603-2006-supplement.pdf. Results depend very much on the choice of the data base and/or the input files as well as on the base model setup. Consequently no model results are shown in this technical note. Examples of use will soon be published in upcoming papers of this special issue on "The Modular Earth Submodel System (MESSy)".

\section{Submodel description}

OFFLEM, ONLEM and TNUDGE are implemented as independent submodels in strong adherence to the MESSy standard as described by Jöckel et al. (2005). This also implies a good portability due to the coding in standard Fortran95 (ISO/IEC-1539-1). No compiler-specific language extensions are used. The adherence to the Fortran95 standard has been further checked by application of the Fortran analyser Forcheck ${ }^{2}$. Switching between different emission fields and

\footnotetext{
${ }^{1}$ http://www.mpch-mainz.mpg.de/ joeckel/ncregrid/

${ }^{2}$ http://www.forcheck.nl/
} 


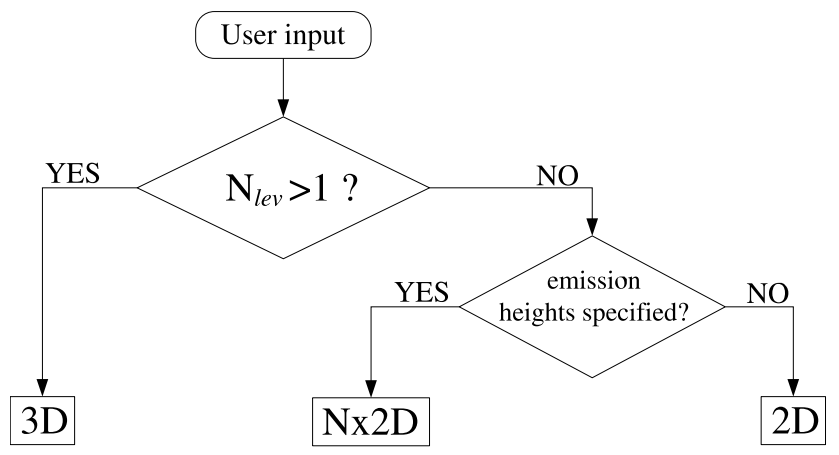

Fig. 1. OFFLEM flowchart: Logic for the determination of the emission type: if the vertical dimension $\left(\mathrm{N}_{\mathrm{lev}}\right)$ of the user defined input field is larger than 1 , the emission type is 3 -D. If the vertical dimension is 1 , the presence of the $\mathrm{z}$-specifier is the marker to distinguish between Nx2D (emission height specified) and 2-D emission type. Note: The vertical dimension $\left(\mathrm{N}_{\mathrm{lev}}\right)$ of a $\mathrm{Nx} 2 \mathrm{D}$ field is 1 , whereas its invariant parameter dimension $\left(\mathrm{N}_{\text {par }}\right)$ equals $\mathrm{N}$.

methods is easy. For instance, adding a new prescribed emission does not require any changes of the program code. Only the emission data file and an additional line in a specific input file have to be provided. A time-consuming recompilation of the code is not necessary. As there is no need for recoding, the submodel is much less prone to produce errors than conventional schemes when adding new species.

As most offline emissions stem from emission data bases, OFFLEM is accompanied by EDGAR2NC, a preprocessing program to convert emission data from the $\mathrm{EDGAR}^{3}$ (Olivier and Berdowski, 2001) format into the netCDF ${ }^{4}$ format required by OFFLEM.

It is not desirable to prescribe all emissions as offline boundary fluxes, in particular for such emissions which strongly depend on the current physical state of the atmosphere, the state of the biosphere (e.g. land use and/or biogeochemistry) and on the hydrological cycle and are therefore highly time dependent. Calculations of those emissions must be performed "online", i.e., during the model simulation, since the species' fluxes vary with time-dependent model parameters. For example, sea salt emissions depend on the wind speed, dust emissions depend on soil properties and wind speed, and biogenic NO emissions change with soil temperature, soil wetness and precipitation. This functionality, i.e. the consideration of changing parameters, is provided by the MESSy submodel ONLEM. Every emission can be switched on/off individually. In contrast to OFFLEM, adding a new online emission requires additional new code: a subroutine with the formulation of the emission parameterization for calculating the emission flux $F_{\text {emis }}$ from the

\footnotetext{
${ }^{3}$ Emission Database for Global Atmospheric Research http:// www.mnp.nl/edgar/

${ }^{4}$ network Common Data Format http://www.unidata.ucar.edu/ software/netcdf/
}

required model parameters and potentially from further prescribed data.

In some cases the emission flux of a species is highly uncertain, or cannot be calculated in the respective simulation (e.g., stratospheric ozone in a simulation focusing on the troposphere). If, however, the mixing ratio distribution of the respective species is known (e.g., from an observational network), it is possible to apply a pseudo-emission by relaxing the simulated mixing ratio of the respective species to the observed mixing ratio. The submodel TNUDGE (Tracer NUDGing) provides this functionality within MESSy.

\subsection{Prescribed emissions (OFFLEM)}

OFFLEM is a submodel managing OFFLine EMissions, i.e., data which have been pre-calculated and stored in files which are read during the model simulation. OFFLEM distinguishes between different emission types and methods, but not between different species classes like e.g. gas phase or aerosol species. Three types of emissions, suitable for different purposes, are distinguished within OFFLEM:

- Surface emissions (2-D): For emissions which occur directly at the interface between land/ocean and atmosphere, e.g. prescribed dimethyl sulfide emissions at the ocean's surface. The corresponding input files contain emission fluxes $F_{\text {emis }}$ in molecules $\mathrm{m}^{-2} \mathrm{~s}^{-1}$.

- Multilayer emissions (Nx2D): For emissions that occur at distinct geometric/specific heights above the surface, such as anthropogenic $\mathrm{SO}_{2}$ emissions (depending on the stack heights), or "effective" emissions calculated by plume models taking into account small scale chemical conversion and additional convection due to heat release (e.g., fire plumes, ship plumes). The corresponding input files contain 3-dimensional fields with distinct fluxes (in molecules $\mathrm{m}^{-2} \mathrm{~s}^{-1}$ ) at $N$ layers. The $N$ geometric heights (meters above ground) can be chosen arbitrarily. They are assigned to the corresponding model layers of the time- and location dependent vertical hybrid-pressure coordinate of the base model. The geometric height is calculated from the geopotential.

- Volume emissions (3-D): For vertically distributed emissions, which are not on distinct geometric levels (e.g., aircraft emissions). The corresponding input files contain 3-dimensional emission rates $\left(R_{\mathrm{emis}}\right.$ in molecules $\mathrm{m}^{-3} \mathrm{~s}^{-1}$ ) on any kind of vertical hybrid pressure or pressure grid.

The emission type is automatically detected by OFFLEM as illustrated in Fig. 1.

Apart from the emission type, three different emission methods are distinguished within OFFLEM:

- Method 0: The chemical species of the atmospheric model, i.e., the tracers, are not directly affected by the 
emission when this method is selected. The imported data is stored in memory for later use by other submodels. A typical application for this method is data import of a climatological field, e.g., a stratospheric ozone distribution derived from satellite observations, which is applied as an upper boundary condition for a tropospheric chemistry simulation. This method is very suitable in connection with TNUDGE (see Sect. 2.3). Note that for this method, the imported field can be in any unit which is suitable for the desired application. The distinction between the different emission types is meaningless for this method.

- Method 1: The change of the mixing ratio $\Delta \mu$ during one model time step $\Delta t$ (i.e. the tracer tendency) is calculated from the prescribed emission flux $F_{\text {emis }}$ and applied to the corresponding tracer:

$$
\begin{array}{ll}
\frac{\Delta \mu}{\Delta t}=\frac{F_{\mathrm{emis}}}{z_{\text {box }}} \times \frac{R T}{p N_{\mathrm{A}}} & \text { for type 2-D and Nx2D } \\
\frac{\Delta \mu}{\Delta t}=R_{\mathrm{emis}} \times \frac{R T}{p N_{\mathrm{A}}} & \text { for type 3-D }
\end{array}
$$

where $z_{\text {box }}$ is the height of the grid box (m), $R=8.314 \mathrm{~J} \mathrm{~mol}^{-1} \mathrm{~K}^{-1}$ is the gas constant, $T$ is the temperature $(\mathrm{K}), p$ is the air pressure $(\mathrm{Pa})$, and $N_{\mathrm{A}}=6.022 \times$ $10^{23} \mathrm{~mol}^{-1}$ is the Avogadro constant. The factor $\frac{R T}{p N_{A}}$ is the inverse of the total number of air molecules. This tendency is then applied by the integration scheme of the base model.

- Method 2: A lower boundary condition for the vertical diffusive flux $F_{\text {vdiff }}$ is calculated from the prescribed emission. This method is only applicable for surface emission fields.

An additional software tool, EDGAR2NC, can be used to convert data from the ASCII-based EDGAR format (usually in $1^{\circ} \times 1^{\circ}$ resolution) into the netCDF format required by OFFLEM (surface or multilayer emissions). The user can "lump" several input files (e.g., various emission classes of one species) together into one netCDF file, and/or distribute them onto multiple emission levels. Further details and an example are provided within the electronic supplement of this paper.

\subsection{Online-calculated emissions (ONLEM)}

Emissions which depend on the actual state of the model (e.g., on the varying meteorological conditions, the wetness of the soil,) are denoted as "online" emissions, since they need to be re-calculated at each time step during the simulation. Such emissions are provided for gas phase and aerosol (particulate) tracers by the ONLEM submodel. In the following details of the currently implemented online emissions will be given:

\subsubsection{Emissions of gas phase tracers}

- Dimethyl sulfide (DMS): The DMS flux $F_{\text {DMS }}$ (molecules $\mathrm{m}^{-2} \mathrm{~s}^{-1}$ ) is calculated by multiplying the DMS seawater concentrations $c_{\mathrm{aq}}(D M S)(\mathrm{mol} / \mathrm{L})$ from Kettle and Andreae (2000) with the piston velocity $k_{\mathrm{w}}$ $(\mathrm{m} / \mathrm{s})$ :

$F_{\mathrm{DMS}}=10^{3} c_{\mathrm{aq}}(D M S) \times k_{\mathrm{w}} \times N_{\mathrm{A}}$

The piston velocity is calculated with the seawateratmosphere exchange algorithm by Liss and Merlivat (1986) using the $10 \mathrm{~m}$ wind speed $v_{10}(\mathrm{~m} / \mathrm{s})$. Depending on $v_{10}$, one of the following equations is used:

$k_{\mathrm{w}}=\left(0.17 \times v_{10}\right)\left(\frac{600}{\mathrm{Sc}}\right)^{2 / 3} \times \frac{0.01}{3600}$

for $v_{10} \leq 3.6 \mathrm{~m} / \mathrm{s}$,

$k_{\mathrm{w}}=\left(2.85 \times v_{10}-9.65\right)\left(\frac{600}{\mathrm{Sc}}\right)^{0.5} \times \frac{0.01}{3600}$

for $3.6 \mathrm{~m} / \mathrm{s}<v_{10} \leq 13 \mathrm{~m} / \mathrm{s}$, and

$k_{\mathrm{w}}=\left(5.9 \times v_{10}-49.3\right)\left(\frac{600}{\mathrm{Sc}}\right)^{0.5} \times \frac{0.01}{3600}$

for $v_{10}>13 \mathrm{~m} / \mathrm{s}$.

Here, $\mathrm{Sc}$ is the Schmidt number $(\mathrm{Sc}=3652.047271-$ $\left.246.99 \times \vartheta_{\text {surf }}+8.536397 \times \vartheta_{\text {surf }}^{2}-0.124397 \times \vartheta_{\text {surf }}^{3}\right)$ and $\vartheta_{\text {surf }}$ is the sea surface temperature $\left({ }^{\circ} \mathrm{C}\right)$.

- $\mathrm{NO}_{\mathrm{x}}$ (nitrogen oxides): The $\mathrm{NO}_{\mathrm{x}}$ soil-biogenic emission flux calculation is based on an implementation of the Yienger and Levy II (1995) semi-empirical emission algorithm according to Ganzeveld et al. (2002). Some additional modifications have been applied as described in detail by Ganzeveld et al. (2006). The calculated flux depends on the one hand on the prescribed distribution of cultivation/agriculture, $\mathrm{N}$-fertilizer loss and on the canopy reduction calculated from the prescribed leaf area index. These fields have to be imported by the data import interface. On the other hand the emission flux is influenced by the soil temperature and the soil wetness which are calculated during the simulation. In addition, the current $\mathrm{NO}_{\mathrm{x}}$ emission flux is affected by the precipitation produced by the model, as $\mathrm{NO}_{\mathrm{x}}$ emissions are significantly increased by precipitation falling after a long dry period, the so-called "pulsing".

- Isoprene and mono-terpene: The algorithm is based on an implementation of the Guenther et al. (1995) algorithm according to Ganzeveld et al. (2002). The emissions vary with the prescribed foliar density, with temperature given by the base model and with the radiative 
conditions within the canopy, which are calculated from the net radiation provided by the base model.

The ONLEM gas phase emissions are assigned to the tracers by the same methods as in OFFLEM: For method 0 , the calculated emission flux is stored in memory for later use. For method 1, the tracer tendency is calculated which is then applied by the integration scheme to the tracer field, and for method 2, the lower boundary condition for the vertical diffusion flux of the tracer is modified. ONLEM provides the possibility to distribute one emission flux onto an arbitrary number of tracers. For instance, the $\mathrm{NO}_{\mathrm{x}}$ can be partitioned between $\mathrm{NO}$ and $\mathrm{NO}_{2}$. For further details see the manual in the electronic supplement.

\subsubsection{Emissions of aerosol tracers}

- Sea salt: For the emission of dry sea salt mass and sea salt particle number two different algorithms are provided, adapted from the implementation by Stier et al. (2005):

1. The first parameterization (called "SS_lsce") by Guelle et al. (2001), (see also references in Stier et al., 2005) is based on pre-calculated lookup tables. Those lookup tables have been calculated using a wind-speed dependent interpolation between the sea salt emission functions by Monahan (1986) and Smith and Harrison (1998). During a model simulation, the wind-speed dependent mass and particle number fluxes for the accumulation mode ( 0.05 to $0.5 \mu \mathrm{m})$ and coarse mode $(0.5$ to $5 \mu \mathrm{m})$ are selected from the lookup tables.

2. In the second parameterization (called "SS_monahan") from Monahan (1986) (see Eq. 25 in that paper) the radius-dependent sea-salt particle number flux $\mathrm{d} F_{N} / \mathrm{d} r\left(\mathrm{~m}^{-2} \mathrm{~s}^{-1} \mu \mathrm{m}^{-1}\right)$ is calculated as follows:

$$
\begin{aligned}
\frac{\mathrm{d} F_{N}}{\mathrm{~d} r}= & 1.37 v_{10}^{3.41} \times r^{-3} \times \\
& \left(1+0.057 r^{1.05}\right) \times 10^{\left(1.19 \exp \left(-B^{2}\right)\right)}
\end{aligned}
$$

where $B=((0.38-\lg r) / 0.65), r$ is the particle radius $(\mu \mathrm{m})$, and $v_{10}$ is the $10 \mathrm{~m}$ wind speed. To avoid extrapolation errors at high wind speeds, a maximum of $v_{10}=20 \mathrm{~m} / \mathrm{s}$ is used for this equation. The radius-dependent sea salt mass flux $\mathrm{d} F_{m} / \mathrm{d} r$ $\left(\mathrm{kg} \mathrm{m}^{-2} \mathrm{~s}^{-1} \mu \mathrm{m}^{-1}\right)$ is correlated to the number flux by:

$$
\frac{\mathrm{d} F_{m}}{\mathrm{~d} r}=\frac{\mathrm{d} F_{N}}{\mathrm{~d} r} \times V_{\text {part }} \times \rho_{\text {part }}
$$

where $V_{\text {part }}$ is the volume of a sea-salt particle $\left(\mathrm{m}^{-3}\right)$ and $\rho_{\text {part }}=1.15 \times 10^{3} \mathrm{~kg} / \mathrm{m}^{3}$ is its density.
Thus, the mass flux is:

$$
\begin{aligned}
\frac{\mathrm{d} F_{m}}{\mathrm{~d} r}= & 1.37 v_{10}^{3.41} \times \frac{4 \pi}{3} \rho_{\text {part }} / 10^{18} \times \\
& \left(1+0.057 r^{1.05}\right) \times 10^{\left(1.19 \exp \left(-B^{2}\right)\right)} .
\end{aligned}
$$

The function is integrated over a small radius range $\Delta r(\mu \mathrm{m})$, yielding the mass flux $F_{m}\left(\mathrm{~kg} \mathrm{~m}^{-2} \mathrm{~s}^{-1}\right)$ :

$F_{m}=\frac{\mathrm{d} F}{\mathrm{~d} r} \times \Delta r$.

For the accumulation mode (as) and the coarse mode (cs), we use the values $r(\mathrm{as})=0.416 \mu \mathrm{m}, \quad r(\mathrm{cs})=3.49 \mu \mathrm{m}, \quad \Delta r(\mathrm{as})=0.5 \mu \mathrm{m}$, and $\Delta r(\mathrm{cs})=4.5 \mu \mathrm{m}$, respectively.

The two sea salt emissions are implemented as independent emissions. As for all other emissions in ONLEM each sea salt emission parameterization is switched via the namelist (see the user manual in the supplement of this paper: http://www.atmos-chem-phys.net/ 6/3603/2006/acp-6-3603-2006-supplement.pdf).

- Dust: The dust emissions subroutine was provided by M. Schulz (LSCE, Saclay, France) for the use in ECHAM5-HAM. Detailed information about this subroutine can be found elsewhere (Balkanski et al., 2003; Schulz et al., 1998; Guelle et al., 2001; Timmreck and Schulz, 2004; Stier et al., 2005). The dust aerosol emission is described as a lognormal distribution with a mass median radius of $2.5 \mu \mathrm{m}$ and a standard deviation of $\sigma=2.0$. The dust emission flux $F_{\text {dust }}\left(\mathrm{kg} \mathrm{m}^{-2} \mathrm{~s}^{-1}\right)$ depends on the $10 \mathrm{~m}$ wind speed $v_{10}$ and various soil parameters, e.g., the source strength factor $f_{\text {src }}$ and the threshold velocity $v_{\text {th }}$, which are provided as input fields.

$$
F_{\text {dust }}=f_{\text {src }} \times\left(v_{10}-v_{\text {th }}\right) \times v_{10}^{2}
$$

In contrast to emissions of gas phase tracers, aerosol emissions cannot be attributed directly to the respective tracers, because the adequate distribution of aerosol matter and particle number strongly depends on the mode or size bin structure of the applied aerosol model. In the current version of ONLEM, the available aerosol emissions are mostly designed to meet the needs of the aerosol model M7 (Vignati et al., 2004), which specifically describes the aerosol distribution in the form of seven lognormal modes.

\subsection{Pseudo emissions (TNUDGE)}

If the flux of a tracer into the atmosphere or a sub-domain cannot be calculated, or this approach is not preferable, the tracer mixing ratio can be prescribed instead. With this, an artificial tracer flux (the pseudo emission) can be diagnosed. This pseudo emission flux can be of either sign. If it is negative, a tracer sink instead of a source is diagnosed. The application of such pseudo emissions is mainly suitable in two cases: 
- Emission fluxes of specific tracers (e.g., CFCs, Halons, etc.) are highly uncertain and/or the tracer lifetime is sufficiently long (e.g. $\mathrm{CH}_{4}$ ), and the atmospheric mixing ratios are well known from observations. In order to achieve a realistic mixing ratio in the model simulation, the respective observed mixing ratios are prescribed as boundary conditions.

- A specific model simulation which does not cover the whole domain and/or complexity requires reasonable boundary conditions. For instance, a model simulation focusing only on tropospheric chemistry processes still requires a reasonable flux of ozone from the stratosphere. This can be achieved by prescribing observed ozone mixing ratios at the tropopause and above.

Tracer mixing ratios are forced to follow a prescribed distribution by applying a relaxation method. The resulting pseudo emissions are diagnosed. An additional tracer tendency is calculated from the difference between the model simulated tracer mixing ratio $\mu$ and the prescribed mixing ratio $\mu_{\text {pre }}$ as

$$
\frac{\Delta \mu}{\Delta t}=-\frac{\mu-\mu_{\mathrm{pre}}}{\Delta t_{n}}
$$

where $\Delta t$ is the model time step and $\Delta t_{n}$ is the relaxation coefficient (or nudging coefficient) in seconds. The nudging coefficient $\Delta t_{n}$ must be larger than (or equal to) $\Delta t$; in case $\Delta t_{n}=\Delta t$, the observed mixing ratio of $x$ is reached in one model time step ("hard nudging"). The flux $F_{\text {emis }}$ (in molecules $\mathrm{m}^{-2} \mathrm{~s}^{-1}$ ) corresponding to Eq. (12) is diagnosed as

$F_{\text {emis }}=\frac{\Delta \mu}{\Delta t} \times z_{\text {box }} \times \frac{p N_{\mathrm{A}}}{R T}$

for surface emissions where $z_{\text {box }}$ is the layer thickness (m). For volume emissions the rate $R_{\mathrm{emis}}$ (in molecules $\mathrm{m}^{-3} \mathrm{~s}^{-1}$ ) is diagnosed as

$R_{\mathrm{emis}}=\frac{\Delta \mu}{\Delta t} \times \frac{p N_{\mathrm{A}}}{R T}$.

The prescribed tracer mixing ratio $\mu_{\text {pre }}$ can be imported by OFFLEM, using emission method 0 (storage in memory, see Sect. 2.1).

\subsection{Integration of the submodels into the MESSy system}

Figure 2 shows the integration of the submodels OFFLEM, ONLEM, and TNUDGE into the overall MESSy framework. OFFLEM and ONLEM import data from different sources via the MESSy data import interface (Jöckel, 2006). OFFLEM input data can be easily preprocessed from the EDGAR database with the preprocessing program EDGAR2NC. Both OFFLEM and ONLEM provide three different methods to deal with the imported/calculated data: The results can be simply stored in memory (method 0 ) for

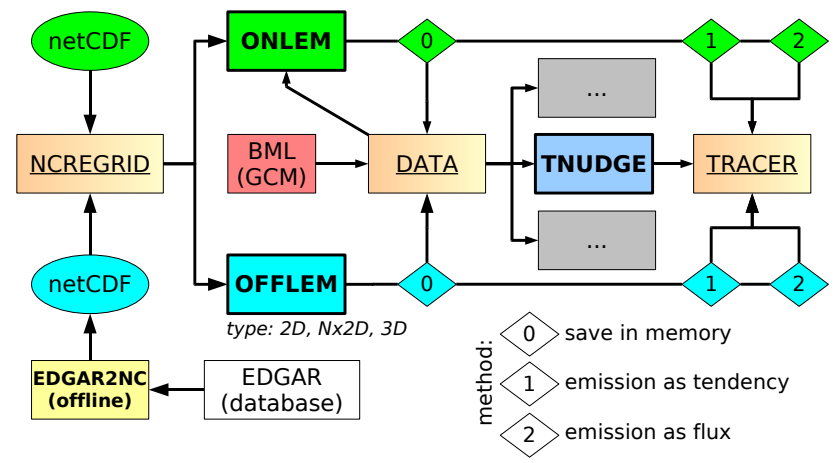

Fig. 2. Data flow between the MESSy submodels OFFLEM, ONLEM, and TNUDGE within the overall MESSy framework. Boxes with color gradation show the generic (infrastructure) MESSy submodels, i.e., the data import interface (NCREGRID), the memory management interface (data transfer/export interface, DATA), and the tracer interface for chemical species (TRACER). BML denotes the MESSy base model layer, e.g., a general circulation model (GCM). Numbers in rhombs indicate the emission method, as explained in the text. The emission type is denoted as 2-D (surface), $\mathrm{Nx} 2 \mathrm{D}$ (multilayer), and 3-D (volume). Note that ONLEM uses data from the base model (delivered via DATA) to calculate the emissions.

use by other submodels (indicated by the grey boxes with dots), an emission tendency can be added to the tracer tendency (method 1), or the lower boundary condition for the vertical diffusion flux of the tracer can be modified (method 2). OFFLEM with method 0 can also be used to import data for TNUDGE, which relaxes a tracer against the imported field.

It is possible to combine several contributions from OFFLEM and ONLEM emissions into one tracer. For example, both the oceanic DMS emissions from ONLEM and prescribed terrestrial DMS emissions (via OFFLEM) can be added to the same DMS tracer.

All three submodels share several design attributes, such as the application of the MESSy import-, data-, and user interface. The structure is highly modular and the code easily portable. Upcoming prescribed emissions can be included via OFFLEM without changes in the code. The effort for implementing new emission parameterizations is greatly reduced by ONLEM. This decreases the risk of potential implementation errors and increases the flexibility and efficiency for the expansion to future applications.

\section{Application within a GCM}

We have used our new submodels in connection with the atmospheric chemistry GCM ECHAM5/MESSy (Roeckner et al., 2006; Jöckel et al., 2005). In this section, some example results are shown to illustrate the capabilities of the new implementation. 

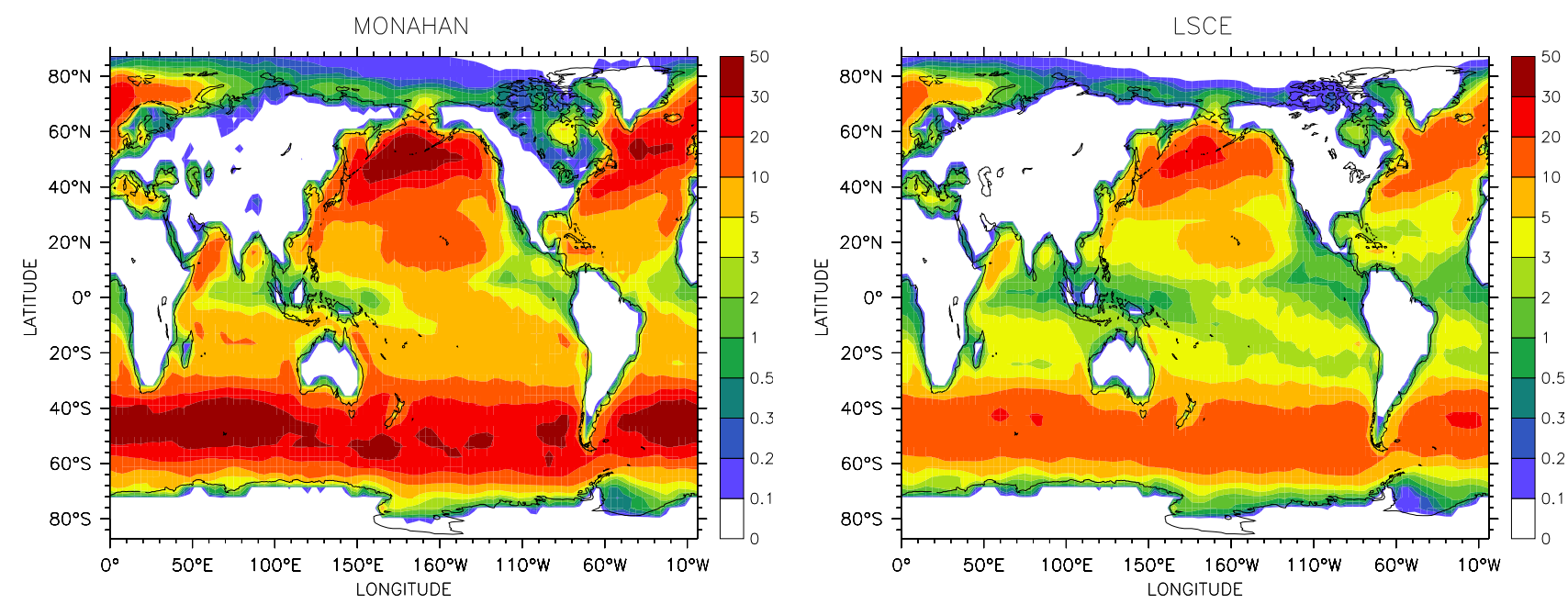

Fig. 3. Annually averaged sea salt emission fluxes $\left(10^{-10} \mathrm{~kg} \mathrm{~m}^{-2} \mathrm{~s}^{-1}\right)$ calculated with the two emission schemes available in ONLEM.
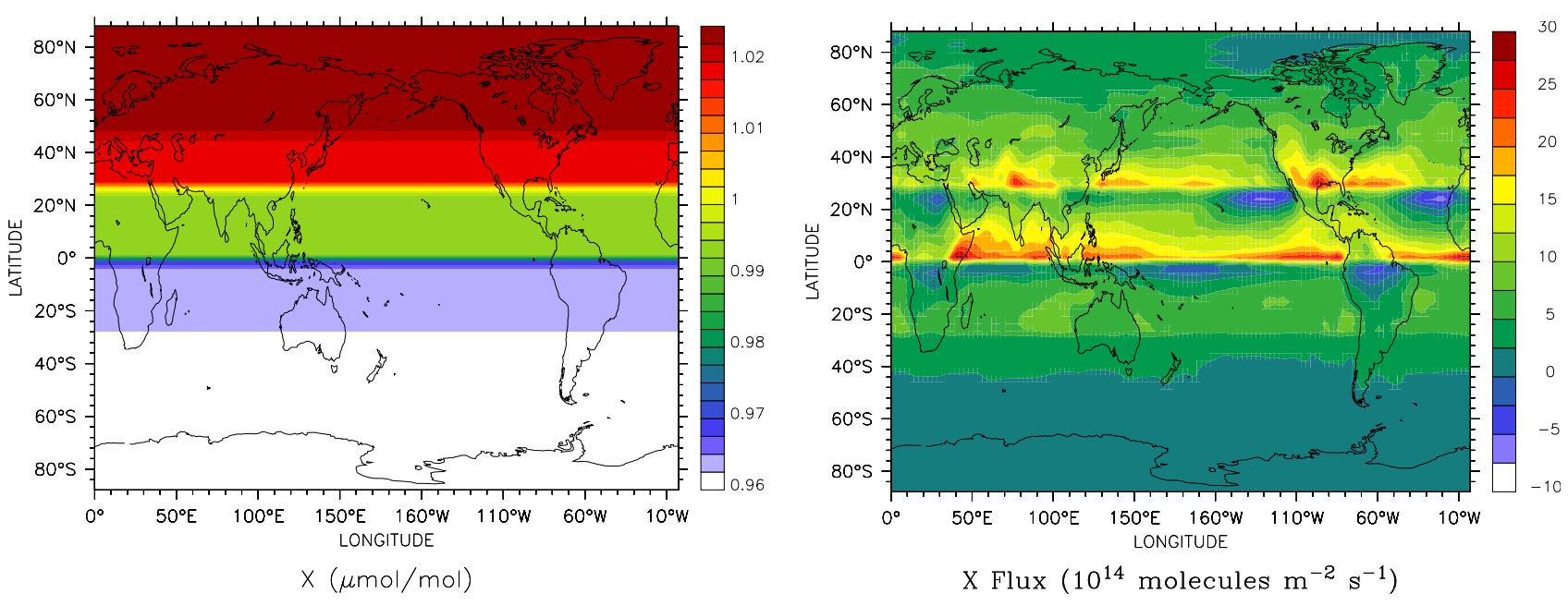

Fig. 4. Left: Annual average of the prescribed mixing ratio $(\mu \mathrm{mol} / \mathrm{mol})$ of the artificial species $\mathrm{X}$ used by TNUDGE for the tracer nudging. Right: Resulting annually averaged X emission/sink flux (in $10^{14}$ molecules $\mathrm{m}^{-2} \mathrm{~s}^{-1}$ ) as diagnosed by TNUDGE.

Figure 3 displays the annually averaged sea salt emission fluxes for both sea salt emission functions available in $\mathrm{ON}$ LEM. The MONAHAN function yields much higher sea salt emission fluxes than the algorithm by M. Schulz (LSCE). The differences between the emission fluxes are highest in regions of high wind speeds (the northern and southern storm track regions), and relatively small in the calmer regions (especially within the ITCZ). This is consistent with several studies (e.g. Guelle et al., 2001; Yang et al., 2005) reporting that the Monahan function produces too high sea salt emissions at higher wind speeds.

Figure 4 shows an example for the use of TNUDGE. $X$ is an artificial species with long lifetime whose most important sink is reaction with $\mathrm{OH}$. The volume mixing ratios of the gas phase tracer $\mathrm{X}$ are relaxed to the annual mean mixing ratios shown on the left hand side of Fig. 4, using a nudging coefficient of $10800 \mathrm{~s}^{-1}$. The right hand side of Fig. 4 depicts the annually averaged $X$ fluxes as diagnosed by TNUDGE. The stepwise increase of the prescribed $\mathrm{X}$ mixing ratios towards the northern latitudes leads to an increased positive flux at the southern border of each step of the prescribed field.

As the emission fluxes and/or budgets resulting from prescribed emissions depend only on the inventories' data base and on the base model, no examples for the use of OFFLEM are given in the context of this technical note. One example of use will be published elsewhere in this special issue (Ganzeveld et al., 2006) utilizing the EDGAR 3.2 Fast Track 2000 emission inventories. 


\section{Summary}

We have presented the new MESSy submodels and tools OFFLEM, ONLEM, TNUDGE, and EDGAR2NC. The high flexibility and the modular nature of the code make them useful also for other models. They are part of the community model MESSy and thus available to our colleagues in atmospheric chemistry and climate research upon request. For details about the availability of the code and the license agreement see http://www.messy-interface.org.

Acknowledgements. We thank M. Schulz, P. Stier and L. Ganzeveld for providing their code for the emission subroutines contained in ONLEM. We thank all other MESSy developers and users for their support. The constructive comments of our four anonymous referees are gratefully acknowledged. We have used the Ferret program (http://www.ferret.noaa.gov) from NOAA's Pacific Marine Environmental Laboratory for creating some of the graphics in this paper.

Edited by: M. Dameris

\section{References}

Balkanski, Y., Schulz, M., Claquin, T., Moulin, C., and Ginoux, P.: Global emissions of mineral aerosol: Formulation and validation using satellite imagery, chap. Emission of Atmospheric Tracer Compounds, pp. 253-282, Kluwer Acad., Norwell, Mass., 2003.

Ganzeveld, L., Lelieveld, J., Dentener, F., Krol, M., and Bouwman, A. J.: Global soil-biogenic $\mathrm{NO}_{x}$ emissions and the role of canopy processes, J. Geophys. Res., 107, 4298, doi:10.1029/2001JD001289, 2002.

Ganzeveld, L., Aardenne, J., Butler, T., Lawrence, M., Metzger, S., Stier, P., Zimmermann, P., and Lelieveld, J.: Technical Note: Anthropogenic and natural offline emissions and the online EMissions and dry DEPosition submodel EMDEP of the Modular Earth Submodel system (MESSy), Atmos. Chem. Phys. Discuss., 6, 5457-5483, 2006, http://www.atmos-chem-phys-discuss.net/6/5457/2006/.

Guelle, W., Schulz, M., Balkanski, Y., and Dentener, F.: Influence of the source formulation on modeling the atmospheric global distribution of sea salt aerosol, J. Geophys. Res., 106, 27 509$27524,2001$.

Guenther, A., Hewitt, C., Erickson, D., Fall, R., Geron, C., Graedel, T., Harley, P., Klinger, L., Lerdau, M., McKay, W., Pierce, T., Scholes, B., Steinbrecher, R., Tallamraju, R., Taylor, J., and Zimmermann, P.: A global model of natural volatile organic compound emissions, J. Geophys. Res., 100, 8873-8892, 1995.
Jöckel, P.: Technical note: Recursive rediscretisation of geoscientific data in the Modular Earth Submodel System (MESSy), Atmos. Chem. Phys., 6, 3557-3562, 2006, http://www.atmos-chem-phys.net/6/3557/2006/.

Jöckel, P., Sander, R., Kerkweg, A., Tost, H., and Lelieveld, J.: Technical Note: The Modular Earth Submodel System (MESSy) - a new approach towards Earth System Modeling, Atmos. Chem. Phys., 5, 433-444, 2005, http://www.atmos-chem-phys.net/5/433/2005/.

Kettle, A. and Andreae, M.: Flux of the dimethylsulfide from the ocean: A comparison of updated data sets and flux models, J. Geophys. Res., 105, 26 793-26 808, 2000.

Liss, P. and Merlivat, L.: The Role of Air-Sea Exchange in Geochemical Cycling, chap. Air-Sea Gas Exchange Rates: Introduction and Synthesis, pp. 113-127, D. Reidel Publishing Company, 1986.

Monahan, E. C.: The Role of Air-Sea Exchange in Geochemical Cycling, chap. The Ocean as a Source for Atmospheric Particles, pp. 129-163, D. Reidel Publishing Company, 1986.

Olivier, J. and Berdowski, J.: The Climate System, chap. Global emissions sources and sinks, pp. 33-78, A.A. Balkema Publishers/Swets \& Zeitlinger Publishers, Lisse, The Netherlands, 2001.

Roeckner, E., Brokopf, R., Esch, M., Giorgetta, M., Hagemann, S., Kornblueh, L., Manzini, E., Schlese, U., and Schulzweida, U.: Sensitivity of simulated climate to horizontal and vertical resolution in the ECHAM5 atmosphere model, J. Climate, 19, 3771-3791, 2006.

Schulz, M., Balkanski, Y., Guelle, W., and Dulac, F.: Role of aerosol size distribution and source location in a threedimensional simulation of a Saharan dust episode tested against satellite-derived optical thickness, J. Geophys. Res., 103, 10 579-10 592, 1998.

Smith, M. H. and Harrison, M.: The Sea Spray Generation Function, J. Aer. Sc., 29, pp. S189-S190, suppl. 1, 1998.

Stier, P., Feichter, J., Kinne, S., Kloster, S., Vignati, E., Wilson, J., Ganzeveld, L., Tegen, I., Werner, M., Balkanski, Y., Schulz, M., and Boucher, O.: The Aerosol-Climate Model ECHAM5-HAM, Atmos. Chem. Phys., 5, 1125-1156, 2005, http://www.atmos-chem-phys.net/5/1125/2005/.

Timmreck, C. and Schulz, M.: Significant dust simulation differences in nudged and climatological operation mode of the AGCM ECHAM, J. Geophys. Res., 109, doi:10.1029/2003JD004381, 2004.

Vignati, E., Wilson, J., and Stier, P.: M7: An efficient size-resolved aerosol microphysics module for large-scale aerosol transport, J. Geophys. Res., 109, D22202, doi:10.1029/2003JD004486, 2004

Yang, X., Cox, R. A., Warwick, N. J., Pyle, J. A., Carver, G. D., O'Connor, F. M., and Savage, N. H.: Tropospheric bromine chemistry and its impacts on ozone: A model study, J. Geophys. Res., 110, doi:10.1029/2005JD006244, 2005.

Yienger, J. and Levy II, H.: Empirical model og global soil-biogenic $\mathrm{NO}_{\mathrm{x}}$ emissions, J. Geophys. Res., 100, 11 447-11 464, 1995. 